\title{
Gastos públicos com a educação básica
}

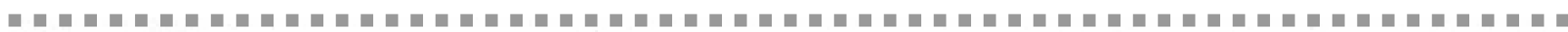
Jorge Abrahão de Castro

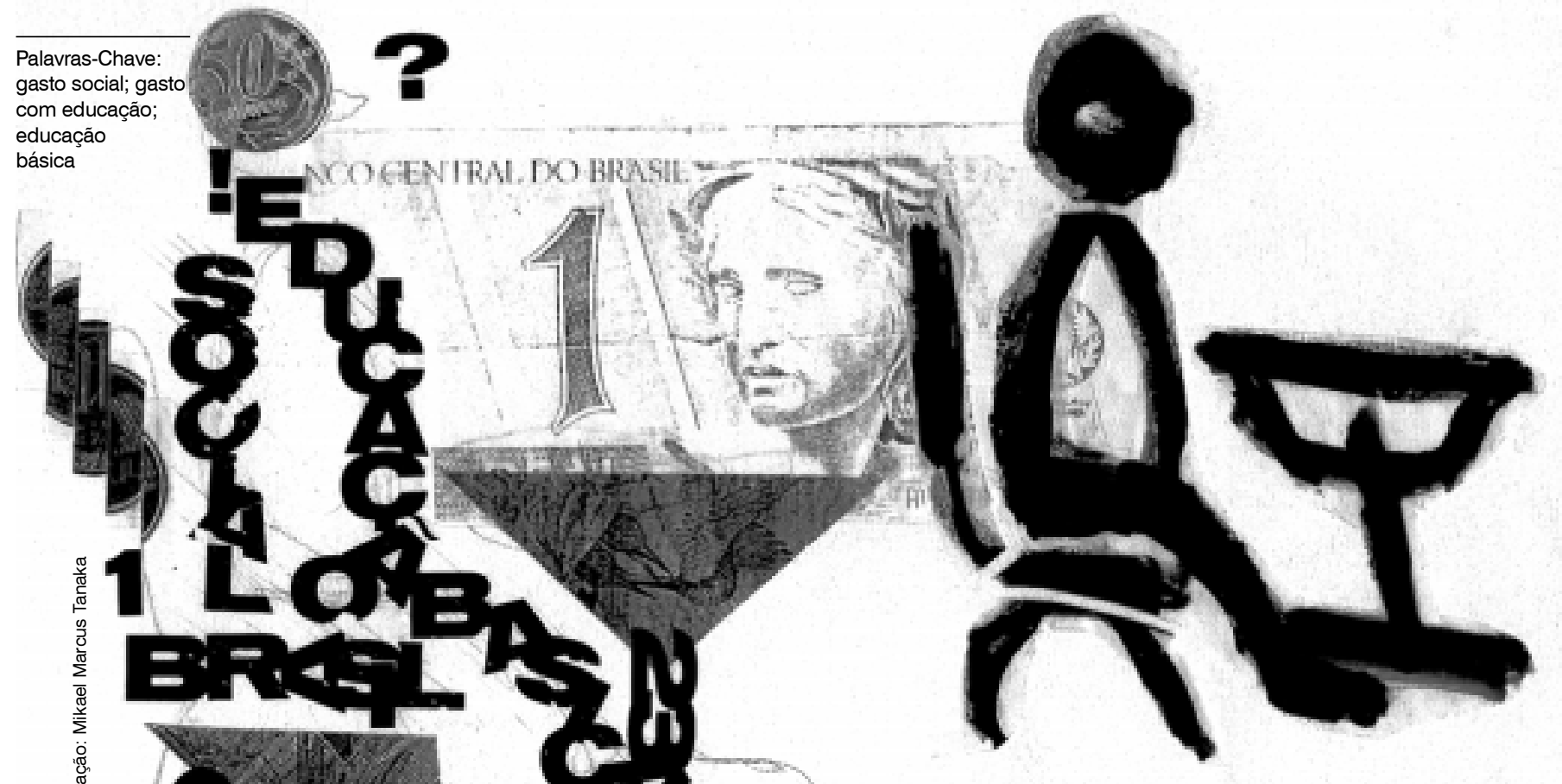

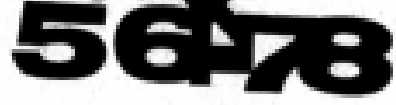



M

ostra, a partir de indicadores financeiros, a dimensão e a estrutura dos gastos públicos realizados na área de educação básica, tomando como base os dados do ano de 1995 das três esferas da federação, provenientes do Sistema de Informações sobre os Gastos Públicos da Área de
Educação (Sigpe) do Instituto de Pesquisa Econômica Aplicada (Ipea). Os resultados do diagnóstico dos gastos com educação para 1995 confirmam a importância da educação básica na área, corroborando sua posição de pilar da educação pública brasileira. Confirmam também que os Estados e municípios são as instâncias federadas que mais se ocupam com a educação básica, respondendo pela grande maioria dos gastos realizados $e$ comprometendo parcela razoável de seus recursos. 


\section{Introdução}

Avaliar os gastos públicos aplicados na educação dos brasileiros é de grande importância para a formulação e implementação das políticas educacionais, uma vez que os recursos públicos, ao propiciarem as principais condições materiais para viabilizar as políticas, podem representar um limite e obstáculo intransponível ao atendimento das demandas educacionais, em quantidade e qualidade.

As informações mais recentes mostram que o Brasil investe uma quantia substancial em educação, cerca de $4,2 \%$ do Produto Interno Bruto (PIB), em 1995 (cf. Castro, Fernandes, 1999). A avaliação deste investimento pode ser realizada de diversas formas, pode-se recorrer a comparações no decorrer do tempo ou realizar comparações entre níveis de educação, regiões, esferas de governo e entre países. Um dos tipos de medidas mais importantes e que é adotado na maioria dos países é o que se pretende apresentar a seguir: medidas relacionadas com os recursos públicos gastos na educação e sua importância em relação às demais despesas governamentais, em relação ao PIB e nos níveis de educação, o gasto médio por aluno (matrícula) envolvido em cada nível, assim como o detalhamento das esferas institucionais envolvidas no controle dos gastos realizados.

Este trabalho centra-se no estudo dos gastos da educação básica, por esta constituir uma das questões mais importantes a serem enfrentadas por uma política responsável de educação. Neste sentido, antes de iniciar-se o estudo, é importante esclarecer o que se denomina educação básica. No começo dos anos 80, era corrente atribuir-se a denominação educação básica àquela que compreendia o espaço educativo formal e não-formal, centrado no ensino fundamental e em torno dele, incluindo a educação préescolar, o ensino supletivo, o ensino médio e as ações de assistência ao educando. Compreendendo as seguintes ações educacionais: educação pré-escolar, ensino fundamental (regular e supletivo), alfabetização e valorização do profissional de educação.

Está-se adotando um conceito mais restrito, tratando-se apenas dos gastos relativos apenas do ensino de 0 a 6 anos, ensino fundamental e ensino médio regular. Portanto, não se está utilizando o conceito amplo de educação básica, que inclui: modalidades formais e informais; ações educativas com ou sem grau de escolaridade incluindo, também, as ações de assistência ao educando. Não se identifica a educação básica com escolaridade obrigatória. Embora os dois conceitos estejam bem próximos, na prática, o primeiro é bem mais amplo, tanto em tempo de duração quanto em conteúdo ou modalidades sobre os quais a educação básica pode apresentar-se.

É importante distinguir o conceito de educação básica utilizado e o de necessidade em educação ou mínimo educacional que deve ser assegurado a toda a população. Na literatura internacional, esses conceitos estão estritamente vinculados e refletem o enfoque que atribui uma importância significativa à educação para a redução das desigualdades sociais e regionais e para a eliminação da extrema pobreza. Na concepção, a educação básica é mais ampla que os mínimos educacionais, correspondendo mais a um objetivo desejável a médio e longo prazo e dificilmente viável a curto prazo.

Por último, é importante considerar que o conceito de educação básica pode ter conteúdos diferenciados, em função da clientela a ser atendida, segundo características socioeconômicas, localização e regionalização. Também a duração da educação pode variar, correspondendo, em distintas situações, a diferentes números de anos de escolaridade.

Portanto, este trabalho mostrará, a partir dos indicadores, a dimensão e a estrutura dos gastos públicos realizados na área de educação básica, pelas três esferas de governo, tomando como base os dados do ano de 1995 das três esferas da Federação provenientes do Sistema de Informações sobre os Gastos Públicos da Área de Educação (Sigpe) do Instituto de Pesquisa Econômica Aplicada (Ipea), que é formado por um conjunto de bases de dados que permitem a elaboração de uma série de indicadores sobre os gastos públicos na área de educação. ${ }^{1}$

\section{Gastos públicos com educação básica e na área social, pelas três esferas de governo}

A magnitude do gasto com educação básica em percentagem do gasto público, na área social, é um forte indicador da

\footnotetext{
1 Este sistema possibilita o acompanhamento, dimensionamento e análise dos gastos públicos realizados na área de Educação, utilizando parte das informações que vem sendo trabalhada e desenvolvida pelo Ipea para as diversas áreas de política social desenvolvida pelas três esferas de governo.
} 
importância relativa atribuída à área diante das demais políticas sociais brasileiras. Este indicador é também afetado pelo total de gastos públicos direcionados na defesa dos benefícios sociais.

No caso da educação, o gasto público efetuado pelas três esferas de governo, em 1995 , no conceito de origem dos recursos, ${ }^{2}$ foi de $\mathrm{R} \$ 27$ milhões e 190 mil (Tabela 1). Esse valor corresponde a $20,1 \%$ do esforço de gasto na área social. A distribuição intergovernamental dos gastos é correspondente à divisão prevista na vinculação dos recursos tributários destinados à educação, revelando o caráter descentralizado das ações educacionais de responsabilidade pública, uma vez que os grandes responsáveis pela área são os Estados e municípios, que, em conjunto, responderam por $75,2 \%$ dos gastos; isto significa que esses governos destinaram aproximadamente $32,3 \%$ de seus gastos sociais à educação. No conjunto do esforço público destinado aos setores sociais, os gastos com a educação corresponderam a 40,4\% dos gastos sociais dos Estados e a $32,9 \%$ dos municípios.

Enquanto isso, o governo federal se compromete com apenas $28 \%$ dos gastos da área de educação, o que representa apenas $8,4 \%$ de seus gastos sociais, incluídas neste montante as transferências negociadas (não-constitucionais) para Estados e municípios. Isto decorre do fato de que a Constituição brasileira atribui aos Estados e municípios a responsabilidade pela oferta da educação básica, cabendo ao governo federal apenas a função supletiva. Assim, a maior parte dos recursos aplicados pelo governo federal, na área da Educação, destina-se ao custeio das Instituições Federais de Ensino Superior (Ifes), Escolas Técnicas Federais (ETFs) e Cefets.

Tendo como base o conceito restrito de educação básica, observa-se, na Ta- bela 1, que os gastos realizados em 1995 foram de $\mathrm{R} \$ 20$, 1 bilhões, correspondendo à maioria dos gastos $(74 \%)$ com educação e a cerca de $14,9 \%$ de todos os gastos sociais, demonstrando a importância que os diversos níveis de governo destinam ao desenvolvimento dessas ações diante das demais atividades envolvidas na área de educação. Quando se observa a participação por esfera de governo, percebe-se que esta importância se eleva ainda mais, para os Estados é de $87,4 \%$ e para os municípios chegou a $88,7 \%$, já o governo federal gasta apenas $32 \%$ de seus recursos na educação básica.

Estes dados mostram que a solução dos problemas da educação básica depende principalmente da ação autônoma de Estados e municípios, não competindo ao governo federal atuar diretamente neste nível de ensino, tendo-lhe sido tradicionalmente atribuída a responsabilidade pelo ensino superior. Neste sentido, o Ministério da Educação (MEC), em relação à educação básica, limita-se a ter uma função normativa, supletiva e redistributiva, no sentido de promover tanto a qualidade como a eqüidade dos serviços educacionais oferecidos à população.

\section{Gastos por níveis, ações e esferas de governo, na área de educação}

O panorama dos gastos na área de educação nos principais níveis, tipos de educação e ações desenvolvidas, por esferas de governo, é de grande importância, pois permite distinguir as responsabilidades das esferas de governo na oferta dos diversos níveis educacionais. A distribuição dos gastos é influenciada principalmente pelo número de estudantes envolvidos em cada nível ou ação de governo, que

\footnotetext{
${ }^{2}$ Para consolidação dos gastos sociais, nos três níveis de governo, considera-se os seguintes critérios: 1) origem dos recursos - identifica-se qual esfera de governo financia o dispêndio, o que inclui as transferências negociadas de recursos para os outros níveis governamentais na esfera onde se originou o gasto; e 2) responsabilidade pelo gasto - foram registradas todas as despesas executadas por cada esfera, seja com recursos oriundos da própria esfera de governo, seja com recursos transferidos de ou tros níveis governamentais.
}

Tabela 1 - Gasto social nas áreas de educação e educação básica pelas três esferas de governo - 1995

\begin{tabular}{|l|c|c|r|r|r|r|}
$\begin{array}{l}\text { Esferas de } \\
\text { governo }\end{array}$ & $\begin{array}{c}\text { Social } \\
\text { (a) }\end{array}$ & $\begin{array}{c}\text { Educação } \\
\text { (b) }\end{array}$ & $\begin{array}{c}\text { Educação Básica } \\
\text { (c) }\end{array}$ & (b/a) & (c/a) & (c/b) \\
\hline Federal $^{1}$ & 80.550 & 6.778 & 2.171 & 8,4 & 2,7 & 32,0 \\
\hline Estados & 32.116 & 12.981 & 11.348 & 40,4 & 35,3 & 87,4 \\
\hline Municípios & 22.619 & 7.431 & 6.590 & 32,9 & 29,1 & 88,7 \\
\hline Total & 135.284 & 27.190 & 20.109 & 20,1 & 14,9 & 74,0 \\
\hline
\end{tabular}


Tabela 2 - Gastos públicos nos níveis e ações de educação por esfera de governo - 1995

\begin{tabular}{|c|c|c|c|c|c|c|c|c|c|c|c|}
\hline \multirow{3}{*}{$\begin{array}{l}\text { Níveis e ações } \\
\text { de educação }\end{array}$} & \multirow{2}{*}{\multicolumn{2}{|c|}{ Federal }} & \multirow{2}{*}{\multicolumn{2}{|c|}{ Estadual }} & \multirow{2}{*}{\multicolumn{2}{|c|}{ Municipal }} & \multicolumn{5}{|c|}{ Em R\$ Mil nominais. } \\
\hline & & & & & & & Total & & & & \\
\hline & (a) & $\%$ & (b) & $\%$ & (c) & $\%$ & (d) & $\%$ & $(a / d)$ & (b/d) & (c/d) \\
\hline $\begin{array}{l}\text { Educação Básica } \\
\text { Educação da } \\
\text { criança de }\end{array}$ & 2.171 .343 & 32,0 & 11.348 .338 & 87,4 & 6.589 .422 & 88,7 & 20.109 .102 & 74,0 & 11 & 56 & 33 \\
\hline $\begin{array}{l}0 \text { a } 6 \text { anos } \\
\text { Ensino }\end{array}$ & 39.827 & 0,6 & 555.546 & 4,3 & 1.833 .244 & 24,7 & 2.428 .617 & 8,9 & 2 & 23 & 75 \\
\hline Fundamental & 1.549 .268 & 22,9 & 8.880 .467 & 68,4 & 4.381 .081 & 59,0 & 14.810 .816 & 54,5 & 10 & 60 & 30 \\
\hline Ensino Médio & 582.248 & 8,6 & 1.912 .325 & 14,7 & 375.096 & 5,0 & 2.869 .669 & 10,6 & 20 & 67 & 13 \\
\hline Outros & 4.606 .244 & 68,0 & 1.633 .347 & 12,6 & 842.132 & 11,3 & 7.081 .724 & 26,0 & 65 & 23 & 12 \\
\hline Total & 6.777 .586 & 100,0 & 12.981 .685 & 100,0 & 7.431 .554 & 100,0 & 27.190 .826 & 100,0 & 25 & 48 & 27 \\
\hline
\end{tabular}

Fonte: Ipea/Disoc.

por outro lado é influenciado pela duração de cada nível.

Este indicador não deve ser interpretado como a medida dos recursos destinados à Educação, mas sim como uma medida da distribuição dos recursos entre os níveis, tipos e ações mais relevantes na área de educação. As diferenças dos gastos efetuados entre as esferas de governo, na distribuição dos gastos entre os níveis educacionais, refletem diferenças nas metas e estratégias concernentes às prioridades de cada nível na educação nacional do País, assim como refletem as disposições legais que determinam as funções de cada esfera de governo. No caso do Brasil, a responsabilidade pelo ensino público é assim dividida: a educação infantil cabe aos municípios; o ensino fundamental, aos Estados, ao Distrito Federal e aos municípios; o ensino médio, aos Estados e ao Distrito Federal; a educação superior, à União e aos Estados.

Para efeito dos objetivos deste trabalho, apresenta-se na Tabela 2 o esforço público na área de educação, dividido segundo duas frentes de gastos: na educação básica e em outros níveis e ações educacionais. Para a educação básica, foram destinados $74 \%$ dos recursos da área, e os gastos ocorreram a partir de três níveis educacionais. O primeiro congrega aqueles programas com maior apoio e em que foram realizados os maiores gastos, que é o ensino fundamental, responsável por $54,5 \%$ dos gastos da área; em seguida, estão os programas do ensino médio, 10,6\% dos gastos; e, por último, a educação da criança de 0 a 6 anos comandando uma parcela de gastos, que chegou a $8,9 \%$.

O outro grupo congrega as ações relativas à educação superior, ao ensino suple- tivo e à educação de jovens e adultos, educação física e desporto e à educação especial, além dos gastos relativos a ações que se relacionam indiretamente à educação, como a assistência ao educando e a manutenção das atividades administrativas, conjuntamente, essas ações somaram $26,0 \%$ dos gastos da área de educação.

A estruturação dos gastos também é um bom indicador de como se dividem as responsabilidades na área de educação entre os três níveis de governo. Assim, pode-se ver pela Tabela 2 que grande parte dos outros gastos (principalmente os com educação superior) é de responsabilidade da União, uma vez que seus gastos chegaram a $65 \%$ do que se consome neste subgrupo, seguido de longe pelos Estados com 23\% (quase na sua totalidade, responsabilidade das Instituições de Ensino Superior paulistas e do Estado do Rio de Janeiro).

A realização dos gastos na educação básica é de forte responsabilidade dos Estados, 56\%, seguidos pelos municípios, 33\% e, por último, o governo federal com $11 \%$. No ensino fundamental, observa-se que os Estados são majoritários na realização do gasto (60\%), enquanto que os municípios respondem por uma parcela de $30 \%$. A União teve participação de apenas $10 \%$, que correspondeu à sua ação supletiva e colaborativa com as demais esferas, de acordo com as disposições legais brasileiras.

A mesma disposição legal é válida para o ensino médio, mas, neste caso, a União mantém um grupo de escolas técnicas e agrotécnicas ${ }^{3}$ de modo que sua participação nos gastos chegou a $20 \%$. Os Estados ainda assim foram os responsá-

\footnotetext{
${ }^{3}$ A rede federal de educação atende a 110 mil alunos e é formada por 43 Escolas Agrotécnicas localizadas em sua maioria na área rural, 19 Escolas Técnicas localizadas em grande parte nas capitais, que atendem aos setores industrial e de servicos, e 36 Unidades de Ensino Descentralizadas a elas subordinadas.
} 
veis por aproximadamente $67 \%$ de todos os gastos do subgrupo; aos municípios coube a participação de apenas $13 \%$ e, em sua maioria, os gastos foram realizados por municípios do Estado de Minas Gerais.

Em consonância com a responsabilidade estabelecida pela Constituição de 1998 e que foi reafirmada na nova Lei de Diretrizes e Bases da Educação Nacional (LDB) que atribuiu aos municípios a oferta da educação infantil, observa-se, na Tabela 2 , que o subgrupo educação da criança de 0 a 6 anos (educação infantil) teve $75 \%$ de seus gastos realizados pelos municípios, sendo apenas $25 \%$ realizados pelos demais níveis governamentais.

\section{Gasto médio por aluno na educação básica}

O indicador do gasto médio por aluno procura medir a relação dos gastos efetuados com recursos públicos com a população que é atendida pelos sistemas de ensino; neste caso, deve-se tomar os gastos relativos aos estudantes matriculados nos principais níveis de ensino. ${ }^{4}$

Esta medida reflete não somente

${ }^{4}$ Uma forma de medir é a relação entre os gastos em Educação e o total da população brasileira residente, que revela que o gasto per capita, em 1995, foi de R\$168,69. Outra forma complementar de análise do gasto na área é sugerida por Fernandes et al. (1998b) que é a comparação dos gastos em Educação com o que se convencionou denominar de "população-alvo", ou seja, aquela parcela da população que se enquadra na faixa etária a ser beneficiada por programas governamentais relativos à área. Esse indicador mostra que o gasto per capita resultante para a área de Educação em 1995, foi de $\mathrm{R} \$ 336,75$.

5 Para efeito de construção do indicador, foram agregados, de forma relativa, os gastos correspondentes ao programa: manutenção das atividades administrativas, no valor de $\mathrm{R} \$ 6.053,80$ milhões, em cada nível de ensino. Pretende-se, com isso, conseguir uma aproximação mais realista dos gastos efetuados por aluno/ano. Essa agregação foi realizada mediante uma proxy que tomou como variáveis o número de matrículas, o número de turmas e a quantidade de docentes, em cada nível de ensino, e para cada esfera de governo.

\section{sistema de educação nacional.}

Fonte: Ipea/Disoc
Para o caso brasileiro, Tabela 3 , observa-se que o gasto médio por aluno ${ }^{5}$ começa no nível de educação de 0 a 6 anos no valor de $R \$ 557,00$, valor superior $(21 \%)$ ao observado para os gastos do ensino fundamental, $R \$ 460,00$. No ensino médio, os gastos crescem chegando a $R \$ 682,00$, superior em $48,3 \%$ ao valor gasto com o nível fundamental.

\section{Tabela 3 - Gasto médio por aluno nos principais níveis de ensino da área de educação - 1995}

Em $R \$ 1,00$

\begin{tabular}{l|c}
\multicolumn{1}{|c|}{ Discriminação } & $\begin{array}{c}\text { Gasto médio } \\
\text { por aluno }\end{array}$ \\
\hline Educação da criança & \\
de 0 a 6 anos & 557 \\
Ensino Fundamental & 460 \\
Ensino Médio & 682 \\
\hline
\end{tabular}

Fonte: Ipea/Disoc.

Obs: Os gastos seguem o critério da origem dos recursos.

Para realização de comparações internacionais, torna-se necessário promover adaptações da metodologia do Ipea, por exemplo, para os conceitos utilizados pelas metodologias da Organization for Economic Cooperation and Development (OECD), é preciso somar os subgrupos ensino fundamental, ensino médio, ensino supletivo e educação especial em um único título denominado ensino fundamental e médio, nas três esferas de governo.

\section{Gasto médio por aluno, por níveis de educação e esferas de governo}

Este indicador é de grande importância, uma vez que permite traçar o panorama dos gastos na área de educação, nos

Tabela 4 - Gasto médio por aluno, por níveis e esferas de governo - 1995

\begin{tabular}{|c|c|c|c|c|c|c|c|}
\hline Discriminação & $\begin{array}{l}\text { Federal } \\
\text { (a) }\end{array}$ & $\begin{array}{l}\text { Estadual } \\
\text { (b) }\end{array}$ & $\begin{array}{l}\text { Municipal } \\
\text { (c) }\end{array}$ & $\begin{array}{c}\text { Total } \\
\text { (d) }\end{array}$ & $(a / d)$ & $(b / d)$ & (c/d) \\
\hline \multicolumn{8}{|c|}{ Educação da criança de } \\
\hline Ensino Fundamental & - & 502 & 418 & 460 & - & 1,09 & 0,91 \\
\hline Ensino Médio & 4.495 & 522 & 1.297 & 682 & 6,59 & 0,76 & 1,90 \\
\hline
\end{tabular}

Obs: Os gastos seguem o critério da origem dos recursos que identifica qual esfera de governo financia o dispêndio. 
principais níveis e tipos de educação por esferas de governo. No caso deste artigo, como se está trabalhando apenas com a educação básica, considera-se apenas os níveis: educação de 0 a 6 anos; ensino fundamental; e ensino médio.

Os resultados apresentados na Tabela 4 revelam que o esforço de gasto do governo federal se concentrou no ensino médio, no qual foram gastos $R \$ 4.495,00$, valor bem superior ao realizado pelas demais esferas de governo, aproximadamente seis vezes o valor da média nacional.

Os Estados mantêm dispêndios em quase todos os níveis de ensino da educação básica. Os valores dos gastos médios por aluno se aproximam, mas as diferenças giram em torno de $2 \%$ a $4 \%$ apenas. Ou seja, em termos agregados, os governos estaduais gastam quase o mesmo valor per capita nos níveis de ensino: educação da criança de 0 a 6 anos, ensino fundamental e ensino médio, respectivamente $R \$ 513,00, R \$ 502,00$ e $R \$ 522,00$.

Os municípios mantêm uma estrutura de gasto um pouco mais diferenciada, em que os menores gastos médios por aluno estão relacionados com o ensino fundamental, com $R \$ 418,00$. O gasto com a educação da criança de 0 a 6 anos foi de $R \$ 568,00$, valor cerca de $20 \%$ superior aos do ensino fundamental e superior ao verificado nos Estados. Os gastos per capita com o ensino médio dos municípios são também de sinal trocado, gastando-se mais com o primeiro do que com o segundo, revelando assim a pouca vocação desta esfera de governo na manutenção desses dois níveis de educação.

\section{Gasto médio por aluno \\ e disparidades regionais}

A medida dos gastos per capita por região, níveis de educação e esfera de governos permite que se determine a disparidade dos gastos no interior de cada país. ${ }^{6} \mathrm{Um}$ indicador desta natureza mede o grau de desigualdade da variável gasto médio por aluno, determinada principalmente pelas diferenciações regionais, ou seja, procura captar, em um país com elevada heterogeneidade estrutural, como é a realidade brasileira, à qual se destina o esforço regional no atendimento educacional.

Os resultados apresentados na Tabela 5 , para todas as cinco grandes regiões brasileiras, mostram que é grande a disparidade existente entre as regiões, com o Sudeste se destacando como aquela em que os gastos médios por aluno são mais elevados, em todos os níveis de ensino. Em alguns casos, como na educação da criança de 0 a 6 anos - com gasto médio por aluno de $\mathrm{R} \$ 903,00$ ao ano - , a diferença ultrapassou o triplo do valor gasto nas Regiões Norte e Nordeste. Para maiores detalhes, confira os dados por Estados e responsabilidade dos gastos nas tabelas do Anexo.

As Regiões Norte e Nordeste são aquelas onde se verificaram os piores indicadores no gasto médio por aluno, em todos os níveis de ensino, bastante inferior aos valores gastos pelos Estados da Região Sudeste e ainda bem inferior aos valores alocados pelas Regiões Sul e Centro-Oeste.

\footnotetext{
${ }^{6}$ Um indicador de disparidade dos gastos, de acordo com Barro (1998), mede o grau de desigualdade em uma variável de gasto determinada entre as regiões e localidades do País. O primeiro indicador de disparidade publicado pela OCDE dizia respeito às diferenças inter-regionais no gasto por aluno de educação primária-secundária (OCDE, 1996a).
}

\section{Tabela 5 - Gasto médio com aluno por unidade da Federação, Região e nível de educação - 1995}

\begin{tabular}{|c|c|c|c|c|c|c|c|c|c|c|}
\hline \multirow{2}{*}{ Regiões } & \multicolumn{3}{|c|}{ Educação de 0 a 6 anos } & \multicolumn{3}{|c|}{ Ensino Fundamental } & \multicolumn{4}{|c|}{ Ensino Médio } \\
\hline & Estado & Mun. & Total & Estado & Mun. & Total & Federal & Estado & Mun. & Total \\
\hline $\begin{array}{l}\text { Norte } \\
\text { Nordeste } \\
\text { Sudeste } \\
\text { Sul } \\
\text { Centro-Oeste }\end{array}$ & $\begin{array}{l}356 \\
410 \\
706 \\
468 \\
468\end{array}$ & $\begin{array}{r}226 \\
239 \\
1.017 \\
739 \\
517\end{array}$ & $\begin{array}{l}285 \\
276 \\
953 \\
657 \\
643\end{array}$ & $\begin{array}{l}350 \\
357 \\
581 \\
455 \\
440\end{array}$ & $\begin{array}{l}209 \\
211 \\
696 \\
658 \\
499\end{array}$ & $\begin{array}{l}302 \\
278 \\
608 \\
535 \\
457\end{array}$ & $\begin{array}{l}5.479 \\
4.079 \\
4.881 \\
3.414 \\
4.576\end{array}$ & $\begin{array}{l}347 \\
367 \\
580 \\
486 \\
487\end{array}$ & $\begin{array}{r}584^{1} \\
1.084^{2} \\
428^{3} \\
-\end{array}$ & $\begin{array}{l}499 \\
502 \\
780 \\
591 \\
808\end{array}$ \\
\hline Total & 513 & 568 & 557 & 502 & 418 & 460 & 4.495 & 522 & 767 & 682 \\
\hline
\end{tabular}

Fonte: Ipea/Disoc.

Obs: Os gastos seguem o critério da origem dos recursos que identifica qual esfera de governo financia o dispêndio.

Nota: 1) resultado apenas da Bahia; 2) somente São Paulo; 3) Estados do Paraná e Rio Grande do Sul; 4) apenas o Estado do Pará 
Além disso, a esfera municipal das Regiões Norte e Nordeste apresenta os piores índices; por exemplo, no ensino fundamental o gasto médio por aluno é a metade da média nacional. Espera-se que essa grande diferença possa ser corrigida a partir de 1998 com a implementação do Fundo de Manutenção e Desenvolvimento do Ensino e Valorização do Magistério (Fundef) (cf. Castro, 1998b).

\section{Gasto médio por aluno e disparidade entre os estados}

O gasto por aluno em cada Estado (envolvendo o conjunto do gasto do governo estadual e municipal) e níveis de educação e esfera de governos permite que se determine as disparidades dos gastos entre os Estados que compõem o País. Uma medida com estas características é de fundamental importância na determinação do grau de desigualdade da alocação média dos recursos públicos, determinada pelas diferenciações locais, ou seja, procura captar o esforço dos Estados e municípios no atendimento educacional de sua população. Está também relacionado com

a capacidade de financiamento que cada um dos Estados possui, que é determinado pela estrutura de partilhas dos recursos tributários do País.

Para calcular esse indicador, foram construídas as

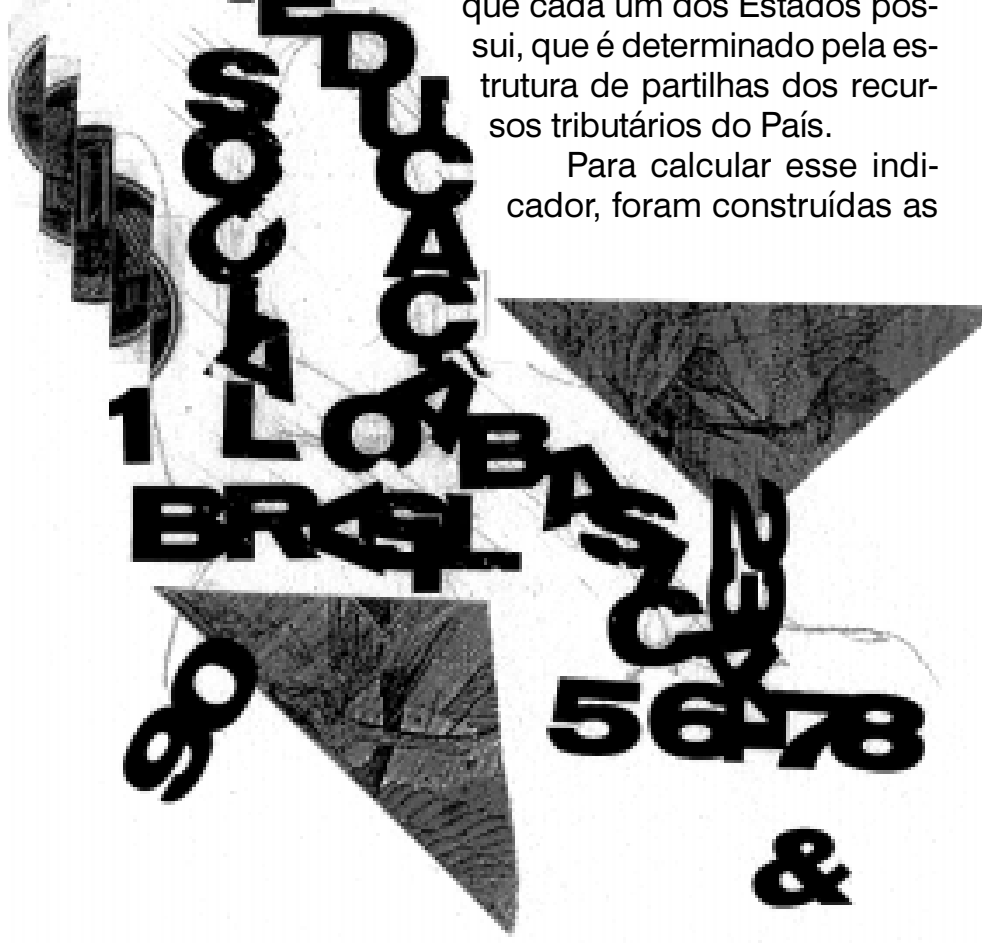

tabelas constantes do Anexo deste artigo, que mostram os gastos médios por aluno, em cada nível de educação, por região e Estado, diferenciando por esfera de governo responsável pelo gasto no interior do Estado. Os resultados da Tabela A1 (Anexo) mostram que, em 1995, os recursos públicos para suportar a educação da criança de 0 a 6 anos, na média nacional, ficaram em $\mathrm{R} \$ 557,00$ por aluno/ano. No entanto, essa medida do gasto médio por aluno varia bastante entre os Estados do País, desde o mais baixo valor $R \$ 191,00$, no Maranhão, até $\mathrm{R} \$ 1.712,00$, no Distrito $\mathrm{Fe}$ deral, ou R\$1.299,00, em São Paulo.

No interior de cada Estado, existe uma grande variação, entre o que cada governo (estadual ou municipal) responsável pelo sistema educacional gasta em termos médios; por exemplo, no Maranhão, os municípios gastaram em educação de 0 a 6 anos apenas $R \$ 150,00$ por aluno, valor bem inferior a $\mathrm{R} \$ 425,00$ que o Estado gastou. Em geral, neste nível educacional, os municípios gastaram mais por aluno que os Estados, $R \$ 568,00$, enquanto os Estados gastaram $R \$ 513,00$.

No Ensino Fundamental, esses fatos voltam a se repetir; assim, enquanto a média nacional de gasto per capita ficou em $R \$ 460,00$, as variações entre os Estados foram enormes (Anexo, Tabela A2). O valor mais baixo foi de $R \$ 216,00$, do Pará, seguido de perto pelo Maranhão com R\$223,00 e pela Paraíba com $\mathrm{R} \$ 240,00$. Por outro lado, no Distrito Federal, os gastos foram de $R \$ 1.635,00$ (este valor envolve a ajuda do governo federal), e em São Paulo, R\$ 63,00 (Gráfico 1). No interior de cada Estado, também, há grande variação no gasto médio por aluno de cada sistema de ensino.

Estes resultados estão associados às responsabilidades legais das esferas de governo, à distribuição dos alunos pelas redes de ensino, assim como parte dessa variação entre os Estados deve-se às diferenças de custos do sistema (manutenção e salários dos profissionais da educação) em cada Estado e município. Além disso, depende da capacidade econômica do Estado; por exemplo, o PIB por aluno para o ano de 1995 do Maranhão foi de apenas $R \$ 1.283,70$, enquanto em São Paulo este valor foi de $\mathrm{R} \$ \mathbf{6 . 8 2 0 , 3 0 \text { e no }}$

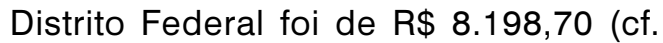
Fernandes et al., 1998b). 


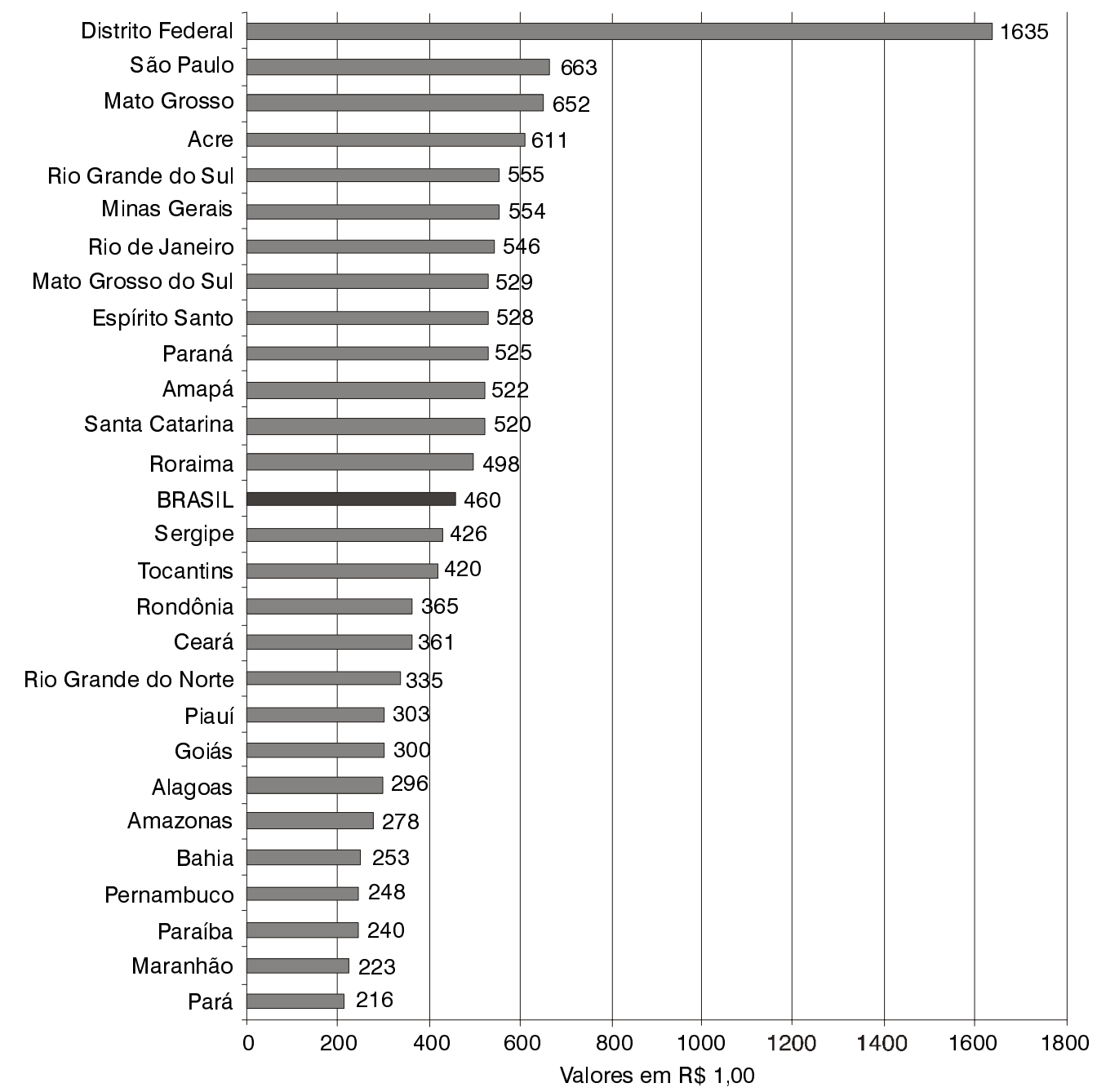

Fonte: Ipea/Disoc.

Gráfico 1 - Gasto médio por aluno para o ensino fundamental - 1995

\section{Conclusões e perspectivas}

Este trabalho apresentou certa quantidade de indicadores que representam um dos conjuntos de informações possíveis de serem elaborados a respeito do gasto público na área de Educação. $O$ acréscimo de mais indicadores e a depuração dos que foram apresentados fazem parte das próximas etapas do trabalho, que deve contar com a participação de pesquisadores e técnicos das instituições interessadas no assunto.

Cabe lembrar que essas medidas não nos dão um quadro completo do financiamento e gasto com educação no País, uma vez que existe também um substancial investimento privado, realizado pelas empresas e pelas famílias, que faz parte das preocupações das principais agências de pesquisa da área.
No entanto, os indicadores educacionais selecionados servem, por exemplo, de referência à análise da natureza e do caráter do federalismo praticado na área de educação, identificando algumas tendências, limitações e possibilidades de gastos da área de educação. Com os resultados do diagnóstico dos gastos na área de educação para 1995, observouse que:

a) a educação é bastante importante nos gastos sociais, reafirmando sua posição de constituir-se um dos pilares da proteção social brasileira;

b) a educação básica é muito importante na área de educação, confirmando sua posição de pilar da educação pública brasileira;

c) a distribuição intergovernamental dos gastos correspondentes às competências 
específicas determinadas a cada esfera do poder público revela o caráter descentralizado das ações governamentais da área. Os Estados e municípios são as instâncias federadas que mais se ocupam com a educação básica, respondendo pela grande maioria dos gastos realizados e comprometendo parcela razoável de seus recursos;

d) o grande esforço de gasto público destinado ao ensino fundamental confirma a prioridade política conferida a esse nível de ensino; em seguida, há os gastos na educação superior, ensino médio e a educação da criança de 0 a 6 anos; e) a distribuição de responsabilidades é bastante nítida, ficando os Estados responsáveis majoritariamente pelo ensino fundamental e médio e os municípios, pela educação infantil.

Este trabalho constitui apenas um primeiro passo, no sentido da sistematização de informações, para possibilitar o gerenciamento eficiente das atividades de operação dos serviços educacionais e o desenvolvimento das funções públicas de formulação, implementação e avaliação das políticas da área de educação, pelas diversas esferas de governo.

\section{Referências bibliográficas}

BARRO, S. M. El desarrollo de indicadores financieros educacionales comparables a nível internacional : la experiencia de la OCDE y sus implicaciones para el Mercosur. In: INDICADORES educacionais comparados en el Mercosur. Santiago, Ago. 1998.

CANADIAN EDUCATION STATISTICS COUNCIL. Education indicators in Canada. PanCanadian Education Indicators Program. Toronto, 1996.

CASTRO, J. A. Federalismo e gasto público em educação no Brasil. Brasília, Revista Brasileira de Estudos Pedagógicos, Brasília, v. 79, n. 192, p. 92-100, maio/ago. 1998a.

. O Fundo de Manutenção e Desenvolvimento do Ensino e Valorização do Magistério (Fundef) e seu impacto no financiamento do Ensino Fundamental. Brasília : Ipea, nov. 1998b. (Texto para Discussão, 604).

CASTRO, J. A., FERNANDES, M. A. Sistema de Informações sobre os Gastos Públicos na Área de Educação (Sigpe) - Diagnóstico dos gastos públicos na área de Educação - 1995. Brasília : Ipea, set. 1999. (Texto para Discussão).

FERNANDES, M. A. et al. Dimensionamento e acompanhamento do gasto social federal. Brasília : Ipea, fev. 1998a. (Texto para Discussão, 547).

. Gasto social consolidado - 1995. Brasília : Ipea, jun. 1998b. (Texto para Discussão).

MCMEEKIN, R. W. Estatisticas Educativas en America Latina y el Caribe. In: INDICADORES educacionais comparados en el Mercosur. Santiago, Ago. 1998.

MEDICI, A. C., MACIEL, M. C. A dinâmica do gasto social nas três esferas de governo 1980-1992. In: DESCENTRALIZAÇÃO e políticas sociais. São Paulo : Fundap, 1996. $376 \mathrm{p}$.

MILLA, J. I. Sistemas de Indicadores de la OCDE y cuestionario UOE. Aplicación de los indicadores de la OCDE : Caso España. In: INDICADORES educacionais comparados en el Mercosur. Santiago, Ago. 1998.

NATIONAL CENTER FOR EDUCATION STATISTICS. Education in States and Nations. Indicators comparing U.S. States with other industrialized countries in 1991. Washington, DC, 1996a. 
NATIONAL CENTER FOR EDUCATION STATISTICS. Education indicators : an international perspective. Washington, DC, nov. 1996b.

. International Education Indicators : a time series perpective. Washington, DC, 1997a. . State Indicators in Education, 1997. Washington, DC, 1997b.

OFFICE FÉDÉRAL DE LA STATISTIQUE (OFS). Les indicateurs de l' enseignement en Suisse. Berne, 1993.

ORGANIZATION FOR ECONOMIC COOPERATION AND DEVELOPMENT (OECD). Education at a glance : OCDE - Indicators. Paris, 1996a.

. Education at a glance : analysis. Paris, 1996b.

Recebido em 15 de outubro de 1999.

Jorge Abrahão de Castro é membro da Diretoria de Políticas Sociais do Instituto de Pesquisas Econômicas e Aplicadas (Ipea) e professor do Departamento de Economia da Universidade Católica de Brasília (UCB).

\section{Abstract}

Based upon financial indicators, this study shows the dimension and structure of public spending in the basic education area, at the year of 1995 and the three federative levels of government. The results confirm that basic education is a very important segment of the education sector, which reinforce its pillar position of the brazilian public education and that states and (provinces) municipalities are the federative instances that are more concerned with basic education, responsible for the maiority of current spendings and a reasonable portion of their resources.

Key-Words: social expenditure; education expenditure; basic education. 


\section{Anexo}

Tabela A1 - Gasto médio por aluno na educação da criança de 0 a 6 anos, por região e Estados - 1995

Em R\$

Região e Estados
NORTE

\begin{tabular}{|c|}
\hline \multicolumn{2}{|c}{ Educação } \\
\hline Governos Estaduais \\
356
\end{tabular}

Acre

710

Rondônia

552

Amazonas

317

Roraima

Pará

491

Amapá

281

Tocantins

459

NORDESTE

505

Maranhão

410

Piauí

Ceará

Rio Grande do Norte

410
425

475

633

Paraíba

386

Pernambuco

260

Alagoas

Sergipe

314

547

630

340

SUDESTE

706

Minas Gerais

Espírito Santo

Rio de Janeiro

São Paulo

545

417

1.040

1.652

SUL

Paraná

468

Santa Catarina

533

Rio Grande do Sul

473

457

\section{CENTRO-OESTE}

Mato Grosso do Sul

Mato Grosso

Goiás

Distrito Federal

Distrito Federal (incluindo

recursos gov. federal)

468
542

728

293

550

1.712

1.712

\section{TOTAL BRASIL}

\section{3}

568

557

Fonte: Ipea/Disoc.

Fonte: Ipea/Disoc.
Obs: Os gastos seguem o critério da origem dos recursos que identifica qual esfera de governo financia o dispêndio. 
Tabela A2 - Gasto médio por aluno no ensino fundamental por região e Estados - 1995

\begin{tabular}{|c|c|c|c|}
\hline \multirow{2}{*}{ Região e Estados } & \multicolumn{3}{|c|}{ Ensino Fundamental } \\
\hline & Governos Estaduais & Governos Municipais & Total \\
\hline NORTE & 350 & 209 & 302 \\
\hline $\begin{array}{l}\text { Acre } \\
\text { Rondônia } \\
\text { Amazonas } \\
\text { Roraima } \\
\text { Pará } \\
\text { Amapá } \\
\text { Tocantins }\end{array}$ & $\begin{array}{l}728 \\
490 \\
296 \\
459 \\
261 \\
431 \\
458\end{array}$ & $\begin{array}{r}362 \\
134 \\
241 \\
1.782 \\
144 \\
1.095 \\
345\end{array}$ & $\begin{array}{l}611 \\
365 \\
278 \\
498 \\
216 \\
522 \\
420\end{array}$ \\
\hline NORDESTE & 357 & 211 & 278 \\
\hline $\begin{array}{l}\text { Maranhão } \\
\text { Piauí } \\
\text { Ceará } \\
\text { Rio Grande do Norte } \\
\text { Paraíba } \\
\text { Pernambuco } \\
\text { Alagoas } \\
\text { Sergipe } \\
\text { Bahia }\end{array}$ & $\begin{array}{l}373 \\
462 \\
553 \\
338 \\
250 \\
271 \\
496 \\
548 \\
298\end{array}$ & $\begin{array}{l}146 \\
177 \\
236 \\
332 \\
230 \\
226 \\
195 \\
277 \\
209\end{array}$ & $\begin{array}{l}223 \\
303 \\
361 \\
335 \\
240 \\
248 \\
296 \\
426 \\
253\end{array}$ \\
\hline SUDESTE & 581 & 696 & 608 \\
\hline $\begin{array}{l}\text { Minas Gerais } \\
\text { Espírito Santo } \\
\text { Rio de Janeiro } \\
\text { São Paulo }\end{array}$ & $\begin{array}{l}538 \\
410 \\
909 \\
574\end{array}$ & $\begin{array}{r}606 \\
881 \\
320 \\
1.390\end{array}$ & $\begin{array}{l}554 \\
528 \\
546 \\
663\end{array}$ \\
\hline SUL & 455 & 658 & 535 \\
\hline $\begin{array}{l}\text { Paraná } \\
\text { Santa Catarina } \\
\text { Rio Grande do Sul }\end{array}$ & $\begin{array}{l}477 \\
422 \\
455\end{array}$ & $\begin{array}{l}579 \\
770 \\
712\end{array}$ & $\begin{array}{l}525 \\
520 \\
555\end{array}$ \\
\hline CENTRO-OESTE & 440 & 499 & 457 \\
\hline $\begin{array}{l}\text { Mato Grosso do Sul } \\
\text { Mato Grosso } \\
\text { Goiás } \\
\text { Distrito Federal } \\
\text { Distrito Federal (incluindo } \\
\text { recursos gov. federal) }\end{array}$ & $\begin{array}{l}466 \\
637 \\
280 \\
528\end{array}$ & $\begin{array}{l}630 \\
684 \\
341 \\
- \\
-\end{array}$ & $\begin{array}{r}529 \\
652 \\
300 \\
528 \\
\\
1.635\end{array}$ \\
\hline TOTAL BRASIL & 502 & 418 & 460 \\
\hline
\end{tabular}


Tabela A3 - Gasto médio por aluno no ensino médio por região

e Estados - 1995

Em R\$

\begin{tabular}{|c|c|c|c|c|}
\hline \multirow{2}{*}{ Região e Estados } & \multicolumn{4}{|c|}{ Ensino Médio } \\
\hline & $\begin{array}{c}\text { Governo } \\
\text { Federal }\end{array}$ & $\begin{array}{l}\text { Governos } \\
\text { Estaduais }\end{array}$ & $\begin{array}{l}\text { Governos } \\
\text { Municipais }\end{array}$ & Total \\
\hline NORTE & 5.479 & 347 & - & 499 \\
\hline $\begin{array}{l}\text { Acre } \\
\text { Rondônia } \\
\text { Amazonas } \\
\text { Roraima } \\
\text { Pará } \\
\text { Amapá } \\
\text { Tocantins }\end{array}$ & $\begin{array}{c}- \\
- \\
3.881 \\
5.957 \\
6.279 \\
- \\
10.145\end{array}$ & $\begin{array}{l}692 \\
540 \\
290 \\
371 \\
263 \\
382 \\
515\end{array}$ & $\begin{array}{l}- \\
- \\
- \\
- \\
- \\
- \\
-\end{array}$ & $\begin{array}{l}692 \\
590 \\
466 \\
851 \\
455 \\
390 \\
575\end{array}$ \\
\hline NORDESTE & 4.079 & 367 & 584 & 502 \\
\hline $\begin{array}{l}\text { Maranhão } \\
\text { Piauí } \\
\text { Ceará } \\
\text { Rio Grande do Norte } \\
\text { Paraíba } \\
\text { Pernambuco } \\
\text { Alagoas } \\
\text { Sergipe } \\
\text { Bahia }\end{array}$ & $\begin{array}{l}3.631 \\
2.183 \\
4.719 \\
5.269 \\
5.413 \\
2.622 \\
4.427 \\
4.833 \\
6.973\end{array}$ & $\begin{array}{l}392 \\
451 \\
567 \\
337 \\
305 \\
279 \\
520 \\
577 \\
321\end{array}$ & $\begin{array}{l}- \\
- \\
- \\
- \\
- \\
- \\
- \\
- \\
584\end{array}$ & $\begin{array}{l}420 \\
611 \\
627 \\
552 \\
580 \\
356 \\
964 \\
786 \\
466\end{array}$ \\
\hline SUDESTE & 4.881 & 580 & 1.084 & 780 \\
\hline $\begin{array}{l}\text { Minas Gerais } \\
\text { Espírito Santo } \\
\text { Rio de Janeiro } \\
\text { São Paulo }\end{array}$ & $\begin{array}{l}5.628 \\
4.096 \\
5.110 \\
3.211\end{array}$ & $\begin{array}{l}590 \\
392 \\
890 \\
529\end{array}$ & $\begin{array}{c}- \\
- \\
- \\
1.084\end{array}$ & $\begin{array}{r}1.368 \\
559 \\
1.050 \\
550\end{array}$ \\
\hline SUL & 3.414 & 486 & 428 & 591 \\
\hline $\begin{array}{l}\text { Paraná } \\
\text { Santa Catarina } \\
\text { Rio Grande do Sul }\end{array}$ & $\begin{array}{l}1.906 \\
5.895 \\
4.182\end{array}$ & $\begin{array}{l}501 \\
515 \\
449\end{array}$ & $\begin{array}{c}690 \\
- \\
418\end{array}$ & $\begin{array}{l}555 \\
697 \\
584\end{array}$ \\
\hline CENTRO-OESTE & 4.576 & 487 & - & 808 \\
\hline $\begin{array}{l}\text { Mato Grosso do Sul } \\
\text { Mato Grosso } \\
\text { Goiás } \\
\text { Distrito Federal } \\
\text { Distrito Federal (incluindo } \\
\text { recursos gov. federal) }\end{array}$ & $\begin{array}{c}- \\
4.358 \\
4.700 \\
4.740\end{array}$ & $\begin{array}{r}550 \\
737 \\
319 \\
542 \\
\\
1.692\end{array}$ & $\begin{array}{l}- \\
- \\
- \\
-\end{array}$ & $\begin{array}{r}529 \\
930 \\
444 \\
1.657 \\
\\
1.692\end{array}$ \\
\hline TOTAL BRASIL & 4.495 & 522 & 767 & 682 \\
\hline
\end{tabular}

